\title{
User Profiles of Healthcare Professionals in a Chronic Obstructive Pulmonary Disease Care Pathway
}

\author{
Casandra Grundstrom ${ }^{1 *}$, Violeta Gaveikaite ${ }^{2,3^{*}}$, Louise Barkhuus ${ }^{4}$, Nicos Maglaveras ${ }^{2,5}$, \\ Stefan Winter ${ }^{6}$, Ioanna Chouvarda ${ }^{2}$ \\ ${ }^{1}$ M3S, Department of Information Processing Science, University of Oulu, Oulu, Finland \\ ${ }^{2}$ Laboratory of Computing, Medical Informatics and Biomedical Imaging Technologies, Aristotle University of Thessaloniki, Thessaloniki, Greece \\ ${ }^{3}$ Department of Chronic Disease Management, Philips Research, Eindhoven, the Netherlands \\ ${ }^{4}$ Department of Digital Design, IT University of Copenhagen, Copenhagen, Denmark \\ ${ }^{5}$ Department of IEMS in McCormick School of Engineering, Northwestern University, Evanston, Illinois, USA \\ ${ }^{6}$ Department of Chronic Disease Management, Philips Research, Aachen, Germany \\ casandra.grundstrom@oulu.fi, \{violeta.gaveikaite, stefan.winter\}@philips.com, barkhuus@itu.dk, \{nicmag, ioanna\}@med.auth.gr
}

\begin{abstract}
Telehealth is a digital service expected to address healthcare demands by supporting self-management and improving access to healthcare facilities for chronic obstructive pulmonary disease. However, results for telehealth efficacy are conflicting partially because of barriers to adoption by end-users. Developing an understanding of users' needs helps to reduce barriers of adoption by allowing service designers to create meaningful experiences. We conduct interviews as part of a case study in a chronic obstructive pulmonary disease care pathway in Greece. Following a user-centered design approach, we describe the goals, tasks, and needs of healthcare professionals as four user profiles. The implications of our findings bring to light a deeper understanding of the attitudes and perceptions of healthcare professionals towards telehealth, as well as a core set of user needs for telehealth service designers.
\end{abstract}

\section{CCS CONCEPTS}

- Human-centered computing Empirical studies in HCI • Human-centered computing User centered design - Human-centered computing User studies

\section{KEYWORDS}

User-centered design, user profiles, telehealth, healthcare professionals, chronic obstructive pulmonary disease, COPD

\section{ACM Reference format:}

Casandra Grundstrom, Violeta Gaveikaite, Louise Barkhuus, Nicos Maglaveras, Stefan Winter, and Ioanna Chouvarda. 2019. User Profiles of Healthcare Professionals in a Chronic Obstructive Pulmonary Disease Care Pathway. In Proceedings of the $13^{\text {th }}$ EAI International Conference on Pervasive Computing Technologies for Healthcare (PervasiveHealth'19). ACM, Trento, Italy. 8 pages. https://doi.org/10.1145/3329189.3329243

\section{Introduction}

In 2016, the World Health Organization (WHO) declared noncommunicable diseases as the leading cause of death worldwide [41]. More than $60 \%$ of global deaths are the direct result of cardiovascular diseases, cancers, diabetes, and chronic respiratory diseases $[39,40]$. To address this, WHO has set a global target to reduce noncommunicable disease mortality $25 \%$ by 2025 [40]. As the global population is aging and contributing to the demand for healthcare provision [7], the financial implications for health systems are substantial, amounting up to $7 \%$ of a country's gross domestic product [34]. Further considerations of chronic care needs are essential. Nolte et al. [27] argue that chronic disease care needs are unlikely to be met by the traditional fragmented model of care. Therefore, a new model of care needs to be implemented in order to accommodate the shift in care delivery processes and emergent stakeholder needs [23].

There are two key concepts in the field of healthcare policies that attempt to solve conventional care fragmentation and deliver more value for a patient: Integrated Care and Value-Based Healthcare $[11,28]$. Both concepts strongly advocate the idea that the provision of care at a distance will be a key component in the future [28]. One of the possible solutions to provide care at a distance is telehealth [25]. However, there are significant barriers to implementing telehealth into clinical practice [5]. One such barrier to telehealth implementation is adoption by users such as patients and healthcare professionals, which remains mostly unexplored [4,5]. Healthcare professionals are users that work in the healthcare context, they are also referred to as clinicians and include but are not limited to physicians, and nurses [12].

Users in chronic disease contexts vary greatly and have a wide range of goals, tasks, and needs [13,16]. For instance, a patient task 
is to collect health data at home, whereas healthcare professionals are tasked to interpret said data for clinical practice. User-centered design is a methodology to engage with and involve users through the design and development of technology services such as telehealth $[5,13,16,24,26,33]$. User-centered design follows an iterative framework of processes where users are centralized to the design focus [13,17]. Naturally, this requires gathering a comprehensive understanding of the intended users in order to identify, capture, and derive necessary user details [13,21]. Analyzed needs of users can then be purposed to represent the user in a profile to inform service designers and system developers $[13,17]$. Considering the opportunity of telehealth to provide support for chronic diseases at a distance and user-centered design, our research question is:

How can a user-centered design approach capture the goals, tasks, and needs of healthcare professionals as user profiles to inform telehealth design and development processes and minimize adoption barriers?

To address this research question, we present a study of healthcare professionals as users in a chronic disease care pathway. A user-centered design methodology approach is adopted to develop an understanding of user goals, tasks, and needs in the form of a user profile. Our findings shed light on both the process and product of developing user profiles aimed to assist service designers and system developers and begin to break down barriers of telehealth adoption.

\section{Background}

Below, we define telehealth, detail the emergence of telehealth in chronic disease care, and discuss the limitations of telehealth adoption in care pathways. We then review the definition and purpose of user-centered design and explain why user profiles are a valuable tool for understanding users of telehealth systems.

\subsection{Chronic Obstructive Pulmonary Disease and Telehealth}

In this paper, we use chronic obstructive pulmonary disease (COPD) as a case example of a chronic disease. COPD, a highly prevalent disease that is characterized by persistent respiratory symptoms due to airway and/or alveolar abnormalities caused by significant exposure to noxious particles or gases [30]. In the European Union, COPD is the leading contributor for total costs among respiratory diseases [39]. It is expected that by 2030, COPD will be the third cause of mortality worldwide [39] and substantially contributes to a colossal economic encumbrance. Telehealth for COPD is anticipated to help bear this burden by providing support for patient self-management, allow early remote detection of signs and symptoms of COPD decompensation, and improve access to healthcare specialists $[3,25]$. Telehealth is the provision of personalized healthcare over a distance comprised of three clear components: 1) the collection and sharing of patient data through 2) a digital means which is transmitted to healthcare professionals at another location, where
3) healthcare professionals use clinical proficiencies to provide personalized feedback to the patient [35]. However, twenty years of research in the field has not conclusively shown the benefits or efficacy of telehealth for patients or healthcare professionals [38].

As COPD is a complex disease, there are many facets of patient care that telehealth may be capable of supporting such as patient education [31] or physical activity [15]. However, there are varying, and seemingly conflicting outcomes reported in literature supporting either the efficacy of telehealth or large-scale implementation into care pathways. A possible reason why there are still mixed results in studies of telehealth, is in part due to the implementation in various care pathways [5,36]. In 2014, Kayyali et al. [18] concluded that five macro European care pathways were different in referral systems and provision of home services for COPD. All care pathways lacked adequate comorbidity management, the tools to enhance patient adherence, or provide education to informal caretakers. The implementation of a usercentered telehealth systems has been suggested to help manage inadequacies in care pathway management $[5,18]$.

A critical consideration when attempting to transform an existing care pathway, is the end-user's involvement in pre and post development [6]. However, in the current COPD management literature for telehealth, we only have few examples of this approach. One of the best examples is from Brunton et al. [5] who conducted a qualitative meta-synthesis of ten articles for user experiences with telehealth. Four articles aimed at exploring the experiences of both patients and health professionals in the use of telehealth; four explored the experiences of patients only; the remaining two articles explored the experience of health professionals only. The synthesis revealed diverging opinions between patients' and healthcare professionals' attitudes towards telehealth. With patients being generally more positive towards telehealth than healthcare professionals, due to user experience.

\subsection{User-Centered Design and User Profiles}

User-centered design is a well-established and multi-dimensional approach in the fields of Human-Computer Interaction and Information System. All definitions involve an understanding of and engaging with the users throughout the design and development process in order to increase user adoption, and usability of the technology, including telehealth. By overlooking the actual needs and values of users, challenges typically arise. For example, a lack of usability with Electronic Health Record systems in the Nordic countries has been illustrated as an accessibility barrier for several different user groups, including patients and healthcare professionals [12].

The core process of user-centered design normally follows iterative phases for analysis, design, evaluation, and implementation [13,17]. The process of identifying and selecting the actual users is performed early in the 'analysis' design process. Heterogenous user groups within healthcare contexts are typically broken down categorically into healthcare professionals, patients and their caregivers, and administrators [33]. User groups may have some variance in their user needs that can be identified 
User Profiles of Healthcare Professionals in a Chronic Obstructive Pulmonary Disease Care Pathway

early in the user-centered design process, but typically "a core set of common needs" is apparent for similar users [20]. In order to piece together users' needs, there are a variety of techniques to elicit information for designers [29]. This information is then used to describe, assess, and differentiate user tasks and characteristics to inform the creation of user profiles [26]. User profiles are conceptualizations representing users' goals, tasks, and needs in a detailed context for service designers to guide development and implementation of telehealth systems $[13,21]$.

\section{Methods}

In this section, we justify the use of a case study for this article and provide pertinent details surrounding the case, explain the process for data collection and analysis, and declare the ethical considerations for the study.

\subsection{Case Study}

Case studies are a common research method in social sciences that aim at investigating a specific topic or phenomena in great detail [42]. Case studies have flexible options for data collection and analysis, allowing for the selection of the most suitable approach to study the given phenomena. With the intention of protecting the identities of both the participants and the hospital, we will use the moniker 'Asclepius' to refer to the case study setting. The instrumental case study [2] was performed at a public hospital in Northern Greece. Asclepius does not have any current telehealth services, but some are being piloted on a small scale to deliver remote care in the nearby regions. Greece has adopted the GOLD guidelines (Global initiative for chronic Obstructive Lung Disease) into clinical practice [18], and the average patient caseload is between 15-20 cases each week.

\subsection{Data Collection and Analysis}

Four different healthcare professionals were selected for semistructured interviews through convenience sampling as they are the main healthcare professionals involved in care of patients with COPD in Asclepius [8]. The selection of the participants was directed by care pathway literature and the roles of healthcare professionals in COPD [18]. Participants represent at least one of each of the main healthcare professionals for Greece in a COPD care pathway. The roles and characteristics of the healthcare professionals are described in more detail in Table 1.

Semi-structured interviews were conducted based on an interview guide that targeted gaps and opportunities for telehealth implementation in the current care pathway. These were: introductions and understanding the current participant setting including patient groups (context), what is performed in daily processes (tasks and needs), what role telehealth would play in their existing work (tasks and needs), and why current and hypothetical tasks are performed (goals).
PervasiveHealth'19, May, 2019, Trento, Italy

Table 1. Participant Attributes

\begin{tabular}{r|l|l|}
\multicolumn{2}{l}{ Participant } & \multicolumn{1}{l}{$\begin{array}{l}\text { Characteristics from } \\
\text { Kayyali et al. [18] }\end{array}$} \\
\hline \multirow{2}{*}{1} & $\begin{array}{l}\text { Head Nurse - not } \\
\text { COPD specialized }\end{array}$ & Nurses \\
\cline { 2 - 3 } 2 & $\begin{array}{l}\text { General } \\
\text { Physiotherapist } \\
\text { (Pulmonary } \\
\text { Rehabilitation) }\end{array}$ & Physiotherapists \\
\cline { 2 - 3 } 3 & $\begin{array}{l}\text { Resident Physician } \\
\text { (Pulmonologist in } \\
\text { training) }\end{array}$ & Specialist Doctors \\
\cline { 2 - 3 } 4 & Pulmonologist & Specialist Doctors \\
\cline { 2 - 3 } &
\end{tabular}

The interviews were recorded, and transcribed following a denaturalization process [32]. Researchers CG and VG used a thematic analysis approach to code the data specifically for the user profiles by categorizing user-centered themes for goals, tasks, and needs of the participants $[9,13,16]$. The themes were then sorted by type and then explanatory power, such as how a user goal informs the larger task at hand. The user profiles were built to be both representative and informative of user roles [16].

Due to privacy concerns, and because the results are representative of very specific users in a care pathway, certain details were either grouped as a general characteristic (such as years of experience) or were not included. We see this preservation of data can be rectified through further user studies to increase both the understanding of the healthcare professionals as users and minimize potential identification. The results are presented as a high-level aggregate for synthesized goals, tasks, and needs for healthcare professionals in both tabular and narrative form with special attention given to any deviations from the group standard [20].

\subsection{Ethical Declaration and Data Management}

All participants were provided with information about the study beforehand and signed an informed consent form. As all participants were over the age of 18 , and the study focused on attitudes and perspectives of the participants and not patient details, no ethical declaration was determined to be needed. The collected data and informed consent forms are handled following the General Data Protection Regulation requirements.

\section{Results}

The results are presented as profiles of the four participants in the Greek COPD care pathway. Results are visually represented in Table 2 and explained narratively below as six user profile areas: Participant Characteristics, Work Setting, Patient Context, Work Tasks, Telehealth Work Tasks, and Telehealth Goals. 
Table 2. User Profiles of Healthcare Professionals at Asclepius

\begin{tabular}{|c|c|c|c|c|}
\hline & Participant \#1 & Participant \#2 & Participant \#3 & Participant \#4 \\
\hline \multirow{3}{*}{$\begin{array}{l}\text { Gender } \\
\text { Job Type }\end{array}$} & \multicolumn{4}{|c|}{ Participant Characteristics } \\
\hline & Woman & Woman & Woman & Woman \\
\hline & Nurse & Physiotherapist & Medical Doctor & Medical Doctor \\
\hline \multirow{3}{*}{$\begin{array}{l}\text { Job Role } \\
\text { Experience }\end{array}$} & $\begin{array}{l}\text { Head Nurse (not specialized in } \\
\text { COPD) }\end{array}$ & $\begin{array}{l}\text { General Physiotherapist } \\
\text { (including Pulmonary } \\
\text { Rehabilitation) }\end{array}$ & $\begin{array}{l}\text { Resident Physician } \\
\text { (Pulmonologist in training) }\end{array}$ & Pulmonologist \\
\hline & Between 25-30 Years & Between 15-20 Years & Between 1-5 Years & Between 5-10 years \\
\hline & \multicolumn{4}{|c|}{ Work Setting } \\
\hline Setting & Public hospital & Public hospital & Public hospital & $\begin{array}{l}\text { Public hospital \& Private } \\
\text { practice }\end{array}$ \\
\hline $\begin{array}{l}\text { Reporting } \\
\text { Hierarchy }\end{array}$ & Participant $3 \& 4$ & Participant $3 \& 4$ & Participant 4 & Main Decision Maker \\
\hline \multirow[t]{2}{*}{$\begin{array}{r}\text { State of } \\
\text { Care in } \\
\text { Greece }\end{array}$} & $\begin{array}{l}\text { Need more professional } \\
\text { resources to handle support } \\
\text { care demand }\end{array}$ & $\begin{array}{l}\text { Severe legal constraints to } \\
\text { perform work-related tasks }\end{array}$ & $\begin{array}{l}\text { Not enough HCPs to support } \\
\text { the care demand, a need for } \\
\text { further IT training }\end{array}$ & $\begin{array}{l}\text { Wants better training of other } \\
\text { staff to improve workload } \\
\text { distribution }\end{array}$ \\
\hline & \multicolumn{4}{|c|}{ Patient Context } \\
\hline \multirow{3}{*}{$\begin{array}{r}\text { Patient } \\
\text { Population } \\
\text { Patient } \\
\text { Interaction }\end{array}$} & $\begin{array}{l}\text { Patients with a severe case of } \\
\text { COPD or are experiencing a } \\
\text { deteriorating event }\end{array}$ & $\begin{array}{l}\text { Patients graded by ABCD tool } \\
\text { by GOLD Guidelines }\end{array}$ & $\begin{array}{l}\text { Mostly C or D severities } \\
\text { graded by } \mathrm{ABCD} \text { tool by } \\
\text { GOLD Guidelines }\end{array}$ & $\begin{array}{l}\text { Patients graded by ABCD tool } \\
\text { by GOLD Guidelines -usually } \\
\text { overweight, elderly ( } 65+\text { ) with } \\
\text { comorbidities }\end{array}$ \\
\hline & Inpatient & Inpatient & Inpatient & Inpatient \& Outpatient \\
\hline & \multicolumn{4}{|c|}{ Work Tasks } \\
\hline \multirow[t]{2}{*}{ Work Tasks } & $\begin{array}{l}\text { Inpatient Monitoring } \\
\text { - Severe: every } 15 \text { min to an } \\
\text { hour } \\
\text { - Stable: } 3 x \text { over } 8 \text { hours } \\
\text { Escalation } \\
\text { - inform deteriorating } \\
\text { patient status to doctor } \\
\text { Medication Management } \\
\text { - distributes medication } \\
\text { orders } \\
\text { Personal Patient Care } \\
\text { - Feeding } \\
\text { - Hygienic needs } \\
\text { Administration Tasks } \\
\text { - Discharge information }\end{array}$ & $\begin{array}{l}\text { Inpatient Education } \\
\text { - Managing dyspnea } \\
\text { - How to perform physical } \\
\text { activity (walking, stairs) } \\
\text { Evaluation } \\
\text { - Appraise patient capacity } \\
\text { for exercising }\end{array}$ & $\begin{array}{l}\text { Inpatient Management } \\
\text { based on GOLD Guidelines } \\
\text { - Diagnostics } \\
\text { - Medication Treatment } \\
\text { - Lifestyle Advice \& } \\
\text { Behaviors Checking } \\
\text { Stakeholder Management } \\
\text { - For comorbidities } \\
\text { - Treatment plan for non- } \\
\text { pharmacological } \\
\text { management } \\
\text { Administration Tasks } \\
\text { - Patient clinical history } \\
\text { Patient Follow-Up } \\
\text { - Stable: every 3-6 months } \\
\text { - Exacerbating: ad hoc basis }\end{array}$ & $\begin{array}{l}\text { Patient Management based } \\
\text { on GOLD Guidelines } \\
\text { - Diagnostics } \\
\text { - Medication treatment } \\
\text { - Lifestyle Advice \& } \\
\text { Behaviors Checking } \\
\text { Stakeholder Management } \\
\text { - For Comorbidities } \\
\text { - Treatment Plan for Non- } \\
\text { Pharmacological } \\
\text { Management } \\
\text { Administration Tasks } \\
\text { - Patient clinical history } \\
\text { Patient Follow-Up } \\
\text { - Stable: every 3-6 months } \\
\text { - Exacerbating: ad hoc basis }\end{array}$ \\
\hline & \multicolumn{4}{|c|}{ Telehealth Work Tasks } \\
\hline $\begin{array}{r}\text { Telehealth } \\
\text { Needs }\end{array}$ & $\begin{array}{l}\text { Outpatient Remote } \\
\text { Monitoring } \\
\text { - Access to Measurements: } \\
\text { objective (blood pressure, } \\
\text { glucose, temperature, \& } \\
\text { oximetry) \& subjective } \\
\text { (diet) } \\
\text { Patient Follow-Up } \\
\text { - All patients: check-up as } \\
\text { needed with status } \\
\text { prompting }\end{array}$ & $\begin{array}{l}\text { Outpatient Remote } \\
\text { Monitoring } \\
\text { - Access to Measurements: } \\
\text { subjective (coughing } \\
\text { frequency, \& sputum } \\
\text { status) } \\
\text { Patient Follow-Up } \\
\text { - Stable patients: check 1x } \\
\text { week } \\
\text { - Severe patients: check } \\
\text { every } 2 \text { days }\end{array}$ & $\begin{array}{l}\text { Outpatient Remote } \\
\text { Monitoring } \\
\text { - Access to Measurements: } \\
\text { objective (blood pressure, } \\
\text { weight, oxygenation), \& } \\
\text { subjective (HrQoL, } \\
\text { symptoms, sputum) }\end{array}$ & $\begin{array}{l}\text { Outpatient Remote } \\
\text { Monitoring } \\
\text { - Access to Measurements: } \\
\text { Objective (blood pressure, } \\
\text { weight, \& oximetry) } \\
\text { Patient Follow-Up } \\
\text { - every } 3 \text { days or } 1 \mathrm{x} \text { month }\end{array}$ \\
\hline
\end{tabular}


User Profiles of Healthcare Professionals in a Chronic Obstructive Pulmonary Disease Care Pathway

\begin{tabular}{|c|c|c|c|c|}
\hline & $\begin{array}{l}\text { Patient Communication } \\
\text { - Video consultations } \\
\text { - Provide personal support if } \\
\text { there is no care giver } \\
\text { available }\end{array}$ & $\begin{array}{l}\text { Patient Communication } \\
\text { - Video consultations } \\
\text { - Exercise coaching } \\
\text { System Requirements } \\
\text { - Decision Making Support } \\
\text { Tools } \\
\text { - Patient reported outcomes } \\
\text { - Dyspnea status } \\
\text { visualization }\end{array}$ & $\begin{array}{l}\text { Patient Communication \& } \\
\text { Desired Functionalities } \\
\text { - Video consultations } \\
\text { - Patient access to healthcare } \\
\text { professionals in case of } \\
\text { emergency: SMS, email, or } \\
\text { telephone } \\
\text { - Patient diaries } \\
\text { Patient Education } \\
\text { - Self-management: smoking } \\
\text { cessation } \\
\text { System Requirements } \\
\text { - Notification in case of } \\
\text { worsening patient status } \\
\text { - Prevention measures for } \\
\text { user abuse } \\
\text { - Task delegation to: } \\
\text { Specialists, nurses }\end{array}$ & $\begin{array}{l}\text { Patient Communication } \\
\text { \& Desired Functionalities } \\
\text { - Video consultations } \\
\text { - Information \& support for: } \\
\text { smoking cessation (videos), } \\
\text { inhalation techniques, \& } \\
\text { help seeking } \\
\text { - Alerts on Potential Risk } \\
\text { Factors: Weather, \& } \\
\text { Pollution Levels } \\
\text { Patient Education } \\
\text { - Smoking cessation \& } \\
\text { medication adherence } \\
\text { - Dyspnea \& cough } \\
\text { System Requirements } \\
\text { - Manual control } \\
\text { - Live \& accurate data } \\
\text { - Intuitive data visualization } \\
\text { - User personalization } \\
\text { - Guaranteed security } \\
\text { - Task delegation }\end{array}$ \\
\hline & \multicolumn{4}{|c|}{ Telehealth Goals } \\
\hline $\begin{array}{l}\text { Attitude } \\
\text { Towards }\end{array}$ & Positive & Positive & Positive & Positive \\
\hline $\begin{array}{r}\text { Perceptions } \\
\text { of } \\
\text { Telehealth }\end{array}$ & $\begin{array}{l}\text { Relationship with patients } \\
\text { would be different but better, } \\
\& \text { would allow for increased } \\
\text { caring capabilities for patients }\end{array}$ & $\begin{array}{l}\text { Would decrease appointment } \\
\text { waiting time, increase SM } \\
\text { capabilities, improve work } \\
\text { engagement. Feels that the } \\
\text { patient doesn't have the same } \\
\text { capacity to engage with TH as } \\
\text { HCPs do }\end{array}$ & $\begin{array}{l}\text { Helps prevent exacerbations \& } \\
\text { decrease disease progression, } \\
\text { patients would feel safer \& } \\
\text { resources would be better } \\
\text { used. Patient readiness for TH } \\
\text { is uncertain }\end{array}$ & $\begin{array}{l}\text { Delay exacerbations \& } \\
\text { unnecessary re- } \\
\text { hospitalizations, better bi- } \\
\text { directional access between } \\
\text { doctor \& patient. Support is } \\
\text { needed to address patient IT } \\
\text { literacy concerns }\end{array}$ \\
\hline $\begin{array}{r}\text { Telehealth } \\
\text { for Patient } \\
\text { Empower- } \\
\text { ment }\end{array}$ & $\begin{array}{l}\text { Access to better \& more } \\
\text { standard care for those who } \\
\text { live in remote areas with few } \\
\text { health services }\end{array}$ & $\begin{array}{l}\text { Increases the patients' ability } \\
\text { to be engaged \& activated in } \\
\text { SM outside of the hospital } \\
\text { setting }\end{array}$ & $\begin{array}{l}\text { Empower patients to seek help } \\
\text { through the telehealth system } \\
\text { \& better patient } \\
\text { communication }\end{array}$ & $\begin{array}{l}\text { Offer patients better tools to } \\
\text { handle SM activities such as } \\
\text { smoking cessation \& } \\
\text { medication adherence }\end{array}$ \\
\hline
\end{tabular}

Abbreviations - HCPs: healthcare professionals; TH: telehealth; IT: Information Technology; SMS: text message; COPD: Chronic Obstructive Pulmonary Disease; GOLD: Global Initiative for chronic Obstructive Lung Disease; SM: Self-management; HrQoL: Health-related Quality of Life

\subsection{Participant Characteristics}

The first user profile area is 'Participant Characteristics' which displays a limited amount of detail of the participants' demographic information (due privacy concerns). Most notably within this section, is that all the users are women who are quite experienced within their individual job role. However, only participant 4 is specialized as a pulmonologist with participant 3 training to be a pulmonologist. The other two participants have general educations which are used within the COPD context.

\subsection{Work Setting}

'Work Setting' for the second user profile area details the type of setting the healthcare professionals work in. All participants work within the public hospital setting except for participant 4 who also works in private practice. The setting also follows the traditional reporting hierarchy in medicine, where the top of the decisionmaking pyramid is the most specialized and trained (participant 4 in this case). Insight into the current healthcare situation in
Greece was provided by all of the participants. Participants 1 and 3 emphasized the demand on healthcare professionals which cannot be met due to a lack of resources. This pressure is also stressed by participant 4 where there is a need for better workload distribution through training of other support staff. Paradoxically, participant 2 is limited by policy to perform work-related tasks.

\subsection{Patient Context}

The third user profile area 'Patient Context' stipulates the typical or normal patient population for COPD in their specific care pathway. Most patients are mostly classified as severe by the GOLD Guidelines, are over the age of 65, typically overweight, and have comorbidities. A patient might not fall within this description if experiencing an exacerbation or deteriorating event which requires hospitalization. With the notable exception of participant 4 who is also able to visit a patient in a home setting, all participants are limited to only interact with patients who are at the public hospital as inpatients. 


\subsection{Work Tasks}

'Work Tasks' is the fourth section of the user profiles and illustrates the explicit needs of the healthcare professionals to perform their jobs within the COPD clinical care pathway. Participant 2 is conspicuously less comprehensive on the scope of requirements for work tasks. This is due to the very narrow responsibility of a physiotherapist when performing pulmonary rehabilitation - these tasks are physical activity and cough management. Since the patients are mostly only engaged with during their hospital visit, the current work tasks reflect the immediate needs of the patients which are formed in a reactive way, rather than oriented towards future preventative actions.

\subsection{Telehealth Work Tasks}

'Telehealth Work Tasks' are the potential needs of the participants should a telehealth system be implemented. Most apparent is the increasing number of task requirements depending on the hierarchical level of job responsibility. Remote patient monitoring with access to live measurements (with varying degrees of differences for objective and subjective measures) was desired by the participants complimented by functional patient follow-up measures and prompting. Patient communication through video consulting was also emphasized, particularly to support patients with means to access healthcare professionals through new channels such as email.

Smoking cessation was an important point for the medical doctors (participants 3 and 4) who wish to provide support for self-management activities remotely. Smoking cessation is a particularly difficult task for participants in Greece due to policy restrictions and the requirement for further specialization by medical doctors. Medication adherence was another selfmanagement area which participants emphasized, as the medical doctors have to trust the patient will follow the strict medication requirements and have no way to track or verify the validity of the at-home patient process.

Three participants (2, 3, and 4) spoke to specific control requirements they would need should telehealth systems be implemented. Strongly advocated for was that telehealth systems should not take the decision-making power away from the healthcare professionals, but rather help support or simplify their work tasks through methods such as using visualizations. Participants were also concerned with the safety of telehealth systems and highlighted the need for user protection and privacy.

\subsection{Telehealth Goals}

Lastly, 'Telehealth Goals' considered the potential capabilities of telehealth for the users in terms of what they value. All of the participants were positive towards the implementation of telehealth despite having minimal experience with telehealth services. Participants all considered that telehealth would benefit their tasks by supporting their ability to perform job tasks and increase the scope of tasks they can perform outside of the hospital setting. Furthermore, the medical doctors, participants 3 and 4, thought that telehealth would help prevent exacerbations.
The few reservations indicated by the participants were mostly concerns about patient adoption, as they questioned the IT literacy of their elderly and chronically ill patients.

\section{Discussion}

In this section, we will first discuss how our results compare to current literature and COPD telehealth projects, followed by exploring the goals, tasks, and needs of healthcare professionals and what it could mean for the adoption of telehealth in care pathways. Finally, we point to future directions for research and explain the limitations of this study.

\subsection{Comparison with Literature and Similar Projects}

This study contributes to the Kayyali et al. [18] study to map COPD care pathways in Europe as nurses and physiotherapists were unavailable to participate from Greece; three other countries (England, Ireland, and the Netherlands) included nurses and physiotherapists. Participant 1, a nurse, reflected a key finding from the Kayyali et al. [18] study when considering the current state of care in Greece, where a "lack of resources in terms of staff, time constraints, and training" negatively impacts the quality of care healthcare professionals are able to provide. This is further compounded by an apparent lack of information to empower patients to seek help through different mediums (such as email or text message). The challenge of communication was an issue our participants illustrated as a need to be accommodated through telehealth design.

Other projects have successfully piloted remote patient monitoring for COPD such as the United4Health project, which also included end users such as clinicians and patients following a user-centered design process $[33,36]$. The United4Health project emphasized the need to involve all of the heterogenous user groups in the iterative process of designing and implementing an efficacious telehealth solution. By involving your users, details come to light that may previously have been overlooked such as considerations for chronic disease patients and their physical limitations [33,36]. More specifically, COPD patients typically cannot move as quickly or in a standard way, and therefore activity trackers may not be able to accurately track their movements or progress.

\subsection{The Goals, Tasks, and Needs of COPD Healthcare Professionals}

Video consultations are a powerful tool within the telehealth package, and unilaterally desired by our participants. Telehealth enables patient empowerment by allowing patients who are more remotely located or face mental and physical challenges, to reach health services they might otherwise be deprived of [10]. Video consultations to aid in inhaler techniques have been proven to provide a high level of patient satisfaction and improved sustainability over time, especially in more remote areas [22]. Despite this, video consultations have conflicting findings and 
User Profiles of Healthcare Professionals in a Chronic Obstructive Pulmonary Disease Care Pathway

receptions by patients and healthcare professionals. In a recent qualitative systematic review, patients and nurses had mixed feelings when using video consultations for a myriad of reasons including user adoption challenges, or barriers to relationship building between patients and healthcare professionals [19]. The latter being contrary to participant 1's attitude (a nurse), where telehealth was not seen as a threat to her existing patient relationships, rather that telehealth would be nurturing for new and existing relationships [37]. Telehealth tools need to facilitate the different types of relationships that form around patient care. Especially since comorbidity management for COPD requires more than one specialist healthcare professional [24]. Technology for healthcare professionals, and patients, especially elder patients, should be designed simplistically as possible and not fully reliant upon $4 \mathrm{G}$ or video streaming [1] - a critical reflection point for service designers.

A major barrier to implementing telehealth services in general is the adoption of telehealth into clinical practices [3]. Similar studies have reported that healthcare professionals in particular have negative attitudes towards telehealth [5]. However, in our study, by involving the users in the early stages of the design process through user-centered design, we can see clearly that in the case of Asclepius, the users have positively oriented attitudes towards telehealth. All of the healthcare professionals in this study also expressed a desire in some form or another for the patient to be empowered through telehealth for self-management. A finding harmonious with the healthcare paradigm shift towards patient empowerment and away from the traditional reactive biomedical model using telehealth [14]. Despite this positivity towards telehealth, participants expressed concerns about patient adoption due to low perceived patient IT literacy. Studies on patient IT literacy of elderly patients have become popular owing to an aging population and pressures of a changing healthcare ecosystem [21]. Determining and designing for accessibility related challenges, especially due to age or disability, helps to mitigate adoption challenges. Chronic patient capabilities and limitations are a crucial consideration for future telehealth services. Ensuring the involvement of the COPD patient population throughout the design and development processes will help diminish this barrier $[4,17,21]$.

One of unique qualities of the Greek healthcare system is that the treating physician is handling patient care, and in our case study, is represented by the pulmonologist (participant 4). When considering this point in light of other healthcare systems, where the "main gate keeper" is a general practitioner, there are major design implications due to the specialization of this particular user. Exemplified in Table 2.0 of the results, participant 4 has the lengthiest demands for a telehealth system and goes into great detail to convey the importance of her usability needs. Her detailed insight may be due to her being strongly in favor of implementing telehealth and active participation in a telehealth pilot study at Asclepius (not part of our study). Her enthusiasm when discussing telehealth and the potential adoption value speaks to the importance of users' attitudes and exemplifying a
PervasiveHealth'19, May, 2019, Trento, Italy

telehealth usability champion [13,16]. All four of the user profiles were positive towards the implementation of telehealth, contrary to the findings of Brunton et al. [5] where healthcare professionals were generally negative due to minimal involvement in the telehealth decision making process. Demonstrating the importance of user-centered design to involve users throughout the design and development process, ultimately to help overcome barriers to adoption.

\subsection{Future Directions and Limitations}

Future studies should aim at continued saturation of user profiles before creating personas, or iterating design, implementation, and evaluation processes [21,24]. Conceptual and low-fidelity prototypes are two design options available to iterate telehealth services with healthcare professionals [24]. User profiles should also continue to expand to include other users such as patients. Careful consideration should be given to the patient user group, especially for the limitations and capabilities as COPD is a chronic and debilitating illness, making the design of telehealth services more demanding [21].

As with all empirical research, this study is not without its limitations. Case studies lack generalizability power, and our case was only within one care pathway with a small sample of four participants [42]. Another limitation of this study is related to the constraints of healthcare professionals and their restricted time. Further details such as IT capabilities of the users would have ideally been captured in this study and should be included through further qualitative means in the future.

\section{Conclusion}

In conclusion, this study examined how certain telehealth adoption barriers can be overcome through user-centered design. We empirically examined the goals, tasks, and needs of healthcare professionals from within the same COPD care pathway in a Greek public hospital. We presented four user profiles of healthcare professionals and discussed how they contribute to the future design of a holistic telehealth tool for COPD. With implications for service designers and developers.

\section{ACKNOWLEDGMENTS}

We are particularly grateful to the four healthcare professionals from Asclepius for their enthusiasm to share their expertise and experience. Your willingness to give your precious time so generously is greatly appreciated.

Authors CG and VG have received funding from the European Union's Horizon 2020 research and innovation programme Marie Sklodowska-Curie Actions Grant Agreement No. 676201 CHESS - Connected Health Early Stage Researcher Support System. 


\section{REFERENCES}

[1] Cathy Bahr and Nicole Denjoy. 2015. UNIversal solutions in TElemedicine Depolyment for European HEALTH care. Document D5. 5 Industry Report on Telemedicine Legal and Regulatory Framework Version 1.

[2] Pamela Baxter and Susan Jack. 2008. Qualitative Case Study Methodology: Study Design and Implementation for Novice Researchers. The qualitative report 13, 4: 544-559.

[3] Jean Bourbeau and Raquel Farias. 2018. Making sense of telemedicine in the management of COPD. The European Respiratory fournal 51. https://doi.org/10.1183/13993003.00851-2018

[4] Liz Brewster, Gail Mountain, Bridgette Wessels, Ciara Kelly, and Mark Hawley. 2013. Factors affecting front line staff acceptance of telehealth technologies: a mixed-method systematic review. Journal of Advanced Nursing 70, 1: 21-33. https://doi.org/10.1111/jan.12196

[5] Lisa Brunton, Peter Bower, and Caroline Sanders. 2015. The contradictions of telehealth user experience in chronic obstructive pulmonary disease (COPD): A qualitative meta-synthesis. PLoS ONE 10, 10 https://doi.org/10.1371/journal.pone.0139561

[6] Mike Clark and Nick Goodwin. 2010. Sustaining Innovation in Telehealth and Telecare: WSDAN briefing paper. King's Fund, London.

[7] Paul R. Dexter, Douglas K. Miller, Daniel O. Clark, Michael Weiner, Lisa E. Harris, Lee Livin, Isaac Myers, David Shaw, Lea Ann Blue, John Kunzer, and J. Marc Overhage. 2010. Preparing for an Aging Population and Improving Chronic Disease Management. In AMIA Annual Symposium Proceedings, 162166.

[8] Mohamed Elfil and Ahmed Negida. 2017. Sampling methods in Clinical Research; an Educational Review. Emergency 5, 1: e52. https://doi.org/10.1136/eb-2014

[9] Nicola K. Gale, Gemma Heath, Elaine Cameron, Sabina Rashid, and Sabi Redwood. 2013. Using the framework method for the analysis of qualitative data in multi-disciplinary health research. BMC medical research methodology 13,1 : 117.

[10] Donna Goodridge and Darcy Marciniuk. 2016. Rural and remote care. Chronic Respiratory Disease 13, 2: 192-203. https://doi.org/10.1177/1479972316633414

[11] Nick Goodwin. 2016. Understanding Integrated Care. International fournal of Integrated Care 16, 4. https://doi.org/10.5334/ijic.2530

[12] Casandra Grundstrom, Karin Väyrynen, and Minna Isomursu. 2018. Dimensions of Accessibility and Interoperability for Electronic Health Records in the Nordic Countries: A Qualitative Evidence Synthesis of Facilitators and Barriers. In Pacific Asia Conference on Information Systems (PACIS).

[13] Jan Gulliksen, Bengt Göransson, Inger Boivie, Stefan Blomkvist, Jenny Persson, and Åsa Cajander. 2003. Key principles for user-centred systems design. In Behaviour and Information Technology, 397-409. https://doi.org/10.1080/01449290310001624329

[14] Blanca E Himes and Elissa R Weitzman. 2016. Innovations in health information technologies for chronic pulmonary diseases. Respiratory Research 17, 1: 38. https://doi.org/10.1186/s12931-016-0354-3

[15] Åsa Holmner, Karin Wadell, Sara Lundell, Börje Rehn, and Andre Nyberg. 2014 Telehealthcare in COPD: A systematic review and meta-analysis on physical outcomes and dyspnea. Respiratory Medicine 109, 1: 11-26. https://doi.org/10.1016/j.rmed.2014.10.008

[16] Juhani Iivari and Netta Iivari. 2011. Varieties of user-centredness: An analysis of four systems development methods. Information Systems fournal 21, 2: 125153. https://doi.org/10.1111/j.1365-2575.2010.00351.x

[17] ISO. 2009. 9241-210: 2010. Ergonomics of human system interaction-Part 210: Human-centred design for interactive systems. International Standardization Organization (ISO). Switzerland.

[18] Reem Kayyali, Bassel Odeh, Inéz Frerichs, Nikki Davies, Eleni Perantoni, Shona D'arcy, Anouk W. Vaes, John Chang, Martijn A. Spruit, Brenda Deering, Nada Philip, Roshan Siva, Evangelos Kaimakamis, Ioanna Chouvarda, Barbara Pierscionek, Norbert Weiler, Emiel Fm Wouters, Andreas Raptopoulos, and Shereen Nabhani-Gebara. 2016. COPD care delivery pathways in five European Union countries: mapping and health care professionals' perceptions. International journal of chronic obstructive pulmonary disease 11: 2831-2838. https://doi.org/10.2147/COPD.S104136

[19] Marita Koivunen and Kaija Saranto. 2018. Nursing professionals' experiences of the facilitators and barriers to the use of telehealth applications: a systematic review of qualitative studies. Scandinavian fournal of Caring Sciences 32, 1: 2444. https://doi.org/10.1111/scs.12445

[20] Sari Kujala and Marjo Kauppinen. 2004. Identifying and selecting users for usercentered design. In NordiCHI, 297-303. https://doi.org/10.1145/1028014.1028060

[21] Cynthia LeRouge, Jiao Ma, Sweta Sneha, and Kirstin Tolle. 2013. User profiles and personas in the design and development of consumer health technologies. International fournal of Medical Informatics 82, 11: 251-268. https://doi.org/10.1109/HICSS.2010.426
[22] Emily R. Locke, Rachel M. Thomas, Deborah M. Woo, Ethan H.K. Nguyen, Bryson K. Tamanaha, Valerie G. Press, Gayle E. Reiber, Peter J. Kaboli, and Vincent S. Fan. 2018. Using Video Telehealth to Facilitate Inhaler Training in Rural Patients with Obstructive Lung Disease. Telemedicine and e-Health 25, 3 : 230-236. https://doi.org/10.1089/tmj.2017.0330

[23] Katrien Luijkx, Loraine Busetto, Stefano Calciolari, Laura Guadalupe González Ortiz, and Hubertus Johannes Maria Vrijhoef. 2018. Barriers and Facilitators to Workforce Changes in Integrated Care. International fournal of Integrated Care 18, 2: 1-13. https://doi.org/10.5334/ijic.3587

[24] Claudia I. Martínez-Alcalá, Mirna Muñoz, and Josep Monguet-Fierro. 2013. Design and Customization of Telemedicine Systems. Computational and Mathematical Methods in Medicine 2013: 618025. https://doi.org/10.1155/2013/618025

[25] Susannah McLean, Denis Protti, and Aziz Sheikh. 2011. Telehealthcare for long term conditions. BMF 342: d120. https://doi.org/10.1136/bmj.d120

[26] Jakob Nielsen. 1994. Usability engineering. Elsevier.

[27] Ellen Nolte, Cécile Knai, and Richard B. Saltman. 2014. Assessing chronic disease management in European health systems. McGraw-Hill International, Glasgow.

[28] Michael E. Porter and Elizabeth Olmsted Teisberg. 2007. How physicians can change the future of health care. Fournal of the American Medical Association 297, 10: 1103-1111. https://doi.org/10.1001/jama.297.10.1103

[29] Jenny Preece, Yvonne Rogers, and Helen Sharp. 2002. Interaction design: beyond human-computer interaction. John Wiley \& Sons, New York, NY.

[30] Roberto Rodriguez-Roisin, Klaus F. Rabe, Jørgen Vestbo, Claus Vogelmeier, and Alvar Agustí. 2017. Global Initiative for Chronic Obstructive Lung Disease (GOLD) 20th anniversary: a brief history of time. European Respiratory fournal 50: 1700671 .

[31] Kathy L. Rush, Linda Hatt, Robert Janke, Lindsay Burton, Matthew Ferrier, and Meghan Tetrault. 2018. The efficacy of telehealth delivered educational approaches for patients with chronic diseases: A systematic review. Patient Education and Counseling 101, 8: 1310-1321. https://doi.org/10.1016/j.pec.2018.02.006

[32] Ulrike Schultze and Michel Avital. 2011. Designing interviews to generate rich data for information systems research. Information and Organization 21, 1: 116. https://doi.org/10.1016/j.infoandorg.2010.11.001

[33] Berglind Smaradottir, Martin Gerdes, and Rune Fensli. 2015. User-Centered Design of a COPD Remote Monitoring Application Experiences from the EUproject United4Health. Interantional fournal on Adancess in Software 8, 3: 350360 .

[34] Marc Suhrcke, Regina Sauto Arce, Martin McKee, and Rocco Lorenzo. 2008. Economic costs of ill health in the European Region. Copenhagen, World Health Organization. Retrieved April 20, 2019 from http://www.euro.who.int/_data/assets/pdf_file/0004/83443/E93695.pdf

[35] Annette M. Totten, Dana M. Womack, Karen B. Eden, Marian S. McDonagh, Jessica C. Griffin, Sara. Grusing, and William R. Hersh. 2016. Telehealth: Mapping the Evidence for Patient Outcomes From Systematic Reviews. Agency for Healthcare Research and Quality (US), Report No.: 16-EHC034-EF. Retrieved March 5, 2019 from https://www.ncbi.nlm.nih.gov/books/NBK379320/pdf/Bookshelf_NBK379320.p df

[36] United4Health. 2016. Telehealth in Practice: care delivery models from 14 regions in Europe. European commission. Retrieved March 10, 2019 from http://united4health.eu

[37] Ivaylo Vassilev, Alison Rowsell, Catherine Pope, Anne Kennedy, Alicia O'Cathain, Chris Salisbury, and Anne Rogers. 2015. Assessing the implementability of telehealth interventions for self-management support: A realist review. Implementation Science 10, 1: 59. https://doi.org/10.1186/s13012015-0238-9

[38] Richard Wootton. 2012. Twenty years of telemedicine in chronic disease management-an evidence synthesis. Fournal of Telemedicine and Telecare 18, 4: 211-220. https://doi.org/10.1258/jtt.2012.120219

[39] World Health Organization. 2010. Global status report on noncommunicable diseases 2010. Retrieved March 10, 2019 from https://apps.who.int/iris/bitstream/handle/10665/44579/9789240686458_eng.pd f?sequence $=1$

[40] World Health Organization. 2013. 2013-2020 Global action plan for the prevention and control of noncommunicable diseases. 1-13. https://doi.org/10.1007/BF03038934

[41] World Health Organization. 2018. Global Health Estimates 2016: Disease burden by Cause, Age, Sex, by Country and by Region, 2000-2016. Geneva: World Health Organization. Retrieved March 10, 2019 from https://www.who.int/healthinfo/global_burden_disease/GlobalDALY_method_ 2000_2016.pdf?ua=1

[42] Robert K. Yin. 2009. Case Study Research: Design and Methods. Sage Publications. https://doi.org/10.1097/FCH.0b013e31822dda9e 